Revista Portuguesa de Ciência Política | Portuguese Journal of Political Science ISSN: 1647-4090 | ISSN-e: 2184-2078 | 2018, Número 9, Páginas 31-43

\title{
Democracia: de volta ao básico, Aristóteles!
}

\author{
Ivanildo Bezerra de Medeiros* \\ * Universidade Federal de Goiás, Brasil
}

\begin{abstract}
Resumo
Compreender em sua totalidade o conceito de democracia na atualidade é uma tarefa bastante complexa, haja vista, as dimensões e variação das sociedades políticas. Revisitar o pensamento teórico dos antigos pode ser um exercício interessante para de forma comparativa examinar em quê e como o pensamento aristotélico está presente na conceção moderna de democracia. O resultado do exercício comparativo aponta para a existência de forte analogia entre a conceção antiga e moderna de democracia como modo de governo para uma sociedade política.
\end{abstract}

Palavras-chave: deliberação; Democracia; participação; poliarquia; teoria da justiça

\begin{abstract}
Understanding the concept of democracy in its totality today is a rather complex task, given the dimensions and variation of political societies. Revisiting the theoretical thinking of the ancients may be an interesting exercise for comparative examination of what and how Aristotelian thought is present in the modern conception of democracy. The result of this comparative exercise points to the existence of a strong analogy between the old and modern conception of democracy as a mode of government for a political society.
\end{abstract}

Keywords: deliberation; Democracy; participation; polyarchy; theory of justice 


\section{Introdução}

O estudo da política, principalmente a forma da gestão de governo denominada "democracia" é, na atualidade, altamente fragmentado, não existindo, por conseguinte, um conceito que sintetize de forma satisfatória o termo democracia.

Revisitar o conceito de democracia na obra Política, de Aristóteles ${ }^{[1]}$, pode ser um exercício interessante para consolidação do pensamento no que diz respeito ao estudo das teorias democráticas na atualidade. Tal exercício epistêmico é válido do ponto de vista em que a obra aristotélica, primeiro, trata dos conceitos atuais da democracia, depois, faz uma análise política abrangente de sua época. Aristóteles pensa que as constituições políticas são o espaço para discussões de temas como a educação e o aborto, por exemplo.

Ao pensar este trabalho temos em mente que, antes desta tentativa, outros exercícios de natureza comparativa entre democracia dos antigos versus democracia dos modernos foram propostos e executados. Não obstante, o objetivo deste artigo é fazer uma aproximação entre o pensamento aristotélico e as teorias modernas de democracia. Neste caso, uma aproximação simples da estrutura do pensamento aristotélico sobre a construção da forma de governo democrática. Principalmente, sobre as correntes teóricas que pensam a democracia como pluralidade, participação, deliberação e justiça.

Objeções quanto à aproximação comparativa proposta podem advir de questões como as colocadas por Sartori (1994). Para o autor, o conceito atual de democracia tem apenas uma vaga semelhança com o conceito desenvolvido no século v a.C.. Mais que isso, uma grande diferença a se considerar, segundo o autor, é o fato da Polis, à época de Aristóteles, ser uma cidade comunidade, distante do conceito da cidade Estado pensada a partir da obra de Maquiavel.

Não obstante, no nosso entendimento, Aristóteles pensa a cidade com elementos constitutivos, mesmo que embrionários, do que viria a ser a sociedade complexa da atualidade. Desta forma, compreendemos ser possível fazer uma ponte analítica entre os conceitos modernos de democracia e a democracia desenvolvida em Politeia.

Haja vista o espaço reduzido do trabalho não será possível aprofundar a discussão ao nível da Filosofia, restando uma exposição que, a nosso ver, evidencia a inexistência de grandes separações entre a forma democrática de pensar o governo dos antigos da atual.

Na seção 2 iremos demonstrar como o conceito de democracia e a ideia de mudança de regimes pode ser observada de forma aproximativa em Politeia e em Poliarquia. Na seção 3, do mesmo modo, a proposta de democracia deliberativa na atualidade e a ideia deliberacionista em Aristóteles. Na seção 4, a participação política nos dois momentos históricos. Por fim, verificar se a ideia da justiça pensada na atualidade pode ser encontrada na obra aristotélica. 


\section{Caminhos para a poliarquia}

A característica da democracia proposta por Dahl (2012) é a contínua responsividade do governo às preferências de seus cidadãos, considerados politicamente iguais. Mais que isso, para Robert Dahl a plenitude de oportunidades deve ser dada a todos os cidadãos considerados plenos, oportunidade de formular e expressar suas preferências e tê-las igualmente consideradas na conduta do governo.

Para assegurar a existência das oportunidades que o autor chama de fundamentais para a democracia, são necessárias algumas garantias no campo das liberdades individuais e do direito, tais como a liberdade de formar e aderir a organizações; liberdade de expressão; direito ao voto; direito de líderes políticos disputarem apoio; eleições livres e idôneas, bem como, garantia que a informação será produzida de forma igual, por fontes alternativas, e que exista instituições que produzam dependência eletiva na gestão de políticas governamentais.

Em sua obra Política, Aristóteles ${ }^{[2]}$ acredita na existência de várias espécies de democracia, sendo considerada a de primeira espécie, uma que tenha como base fundamental a igualdade, significando a inexistência de soberania entre as classes mais abastadas e outras. Mais que isso, se liberdade e igualdade são fundamentais para a existência da democracia, as mesmas só existem, plenamente, se todos os cidadãos - o cidadão total na visão aristotélica é aquele que adquire o direito de administrar justiça e exercer funções públicas - gozarem da mais perfeita igualdade política.

Para efeito de compreensão analítica, Dahl institui duas dimensões teóricas para mensurar o quanto uma sociedade é democrática. Um eixo denominado liberalização, entendido como contestação pública e outro chamado inclusividade pensado como participação. A partir deste esquema teórico, Robert Dahl propõe três caminhos possíveis para a democracia plena à qual dá o nome de poliarquia. $\mathrm{O}$ caminho (I) parte de um regime que o autor chama de hegemonia fechada para uma oligarquia competitiva, no caminho (II), sai do mesmo ponto e chega a uma hegemonia inclusiva, no caminho (III) segue de forma direta para a poliarquia.

No constructo de Robert Dahl o deslocamento de regimes de hegemonias fechadas para oligarquias competitivas ocorre quando o regime permite maior contestação pública. Quando há maior participação pode-se considerar que o regime está se tornando mais inclusivo, portanto, tomando a direção do que o autor considera o caminho (II). Quando a mudança ocorre em direção à poliarquia, é possível perceber algum grau de democratização nessa sociedade.

Aristóteles ${ }^{[3]}$ também admite a existência de algumas possibilidades de mudança de regimes fechados e oligárquicos para uma democracia plena a partir do que ele entende como revolução. Como há no pensamento do filósofo um tipo de revolução que não visa destituir uma Constituição ou governo, mas apenas assumir o poder, pode-se considerar este tipo como uma forma de oposição ao regime sem uma ideia de reforma, transformação ou mudança completa da Constituição ou do governo.

\footnotetext{
2. Idem nota 1 .

3. Idem nota 1 .
} 
Neste sentido, a oposição ou contestação “pode tratar-se apenas de uma questão de quantidade; por exemplo, quando há uma oligarquia, o objetivo da revolução pode ser a mudança no sentido de torná-la mais ou menos oligárquica, ou quando há uma democracia, para torná-la mais ou menos democrática” (Aristóteles, 1985, p. 1302).

No pensamento de Aristóteles, a mudança de Constituição ou governo pode ocorrer em várias direções, tanto no caminho da democratização quanto no sentido inverso. Não obstante, o autor acredita que todas as Constituições aristocráticas tendem à oligarquia. Do mesmo modo, parece ser este o caminho encontrado no esquema teórico de Dahl em que os regimes partem de uma hegemonia fechada (monarquias/tiranias) para uma oligarquia competitiva.

O princípio fundamental para a forma democrática de governo no pensamento de Aristóteles é a liberdade. Dentro do conceito de liberdade, - que só se pode alcançar em um sistema de governo democrático - a alternância de poder é uma necessidade. De preferência, um sistema que permita ao cidadão governar e ser governado, onde os cargos públicos sejam ocupados de forma eletiva ou por sorteio. Outro princípio importante para a democracia é o direito a uma forma livre de viver, traduzido como liberdade baseada na igualdade, não obstante, Aristóteles considerar uma dificuldade a ser enfrentada nos regimes democráticos a ideia de igualdade e justiça.

Em nossa tentativa de aproximação das teorias democráticas de Aristóteles, e Robert Dahl a expectativa era encontrar, nos dois autores, características na estrutura da definição do conceito de democracia e fundamentações teóricas similares sobre mudança de regimes.

Diante da pequena exposição acima, ficou evidenciada preocupação dos dois autores em demonstrar que a liberdade e a igualdade são os princípios fundamentais garantidores da existência de uma democracia. Da mesma forma, defendem a ideia que os regimes podem mudar em algumas direções, e, quando o rumo da mudança é no sentido de um regime democrático, algumas estruturas como liberdade e direito se fazem presente.

\section{Deliberação como processo de participação}

Na concepção de Amy Gutmann (1995, pp. 5-37) o pensamento democrático deliberativo entende a pessoa como ser independente, com poder de julgamento e tomada de decisão para uma diversificada gama de questões, a partir de um vasto conjunto de considerações, de forma pertinente ao seu pensamento e consideração. Mais que isso, pressupõe que todo adulto é tratado como uma pessoa detentora de determinada autonomia, portanto, lhe é assegurado o status político de igualdade em sua cidadania.

Neste sentido, segundo Gutmann, uma pessoa autônoma é capaz de governar a si com autodeterminação que pode passar a exigir deliberação e envolvimento nas várias facetas das dimensões de sua própria existência, quer em questões de ordem pessoal, ou em problemas da coletividade e da política. Pode-se afirmar que "a democracia deliberativa defende que a liberdade pessoal, assim como a liberdade política, aumenta de valor na medida em que seu exercício exprima ou encoraje a autonomia, 
a capacidade de determinar nossas vidas de acordo com julgamentos bem refletidos" (Gutmann, 1995, p. 20).

Uma corrente de pensamento que defende a democracia deliberativa, como exemplo a representada por Amy Gutmann (1995), propõe respostas a questões tais como a valorização da vontade popular e a liberdade pessoal quando estão expressas em alguma forma de autonomia do cidadão - principalmente se este conceito for compreendido como autodeterminação, e, esta significar disposição e capacidade para orientar o próprio destino - tanto no sentido pessoal como no público, por meio da deliberação, da capacidade de obter informação que transforma em reflexão consciente, do poder de julgar e persuadir para chegar à eloquência e à própria razão.

Para Habermas (1997), o processo da política deliberativa constitui o âmago do processo democrático. Neste sentido, este procedimento ocorre quando o fluxo comunicacional move-se entre a vontade formada publicamente - a partir de prescrições de normas institucionais - e quando da ocorrência de debates para formação das leis. Resulta disto a transformação dessas ações em poder efetivo e aplicável administrativamente, produzido pelo ato de comunicar-se.

A deliberação tinha caráter constitucional na comunidade política aristotélica, inclusive, assumindo poderes soberanos quanto a assuntos que afetavam de forma mais substantiva a sociedade: decisões sobre a guerra, formação e dissolução de alianças, instituição de Leis. "Dar a todos os cidadãos o direito de participar do corpo deliberativo e de tomar decisões sobre todas estas matérias é característico da democracia, pois o povo procura este tipo de igualdade" (1985, p. 1.298).

Nas democracias da Grécia Antiga as formas de participação eram numerosas, podia-se compartilhar das deliberações de forma alternada por grupo de cidadãos, deliberava-se a partir dos conselhos de funcionários conjuntamente em assembleias. Neste caso, a deliberação ocorria, ora cada tribo em separado, noutra em pequenos grupos de cidadãos. A participação dizia respeito à legislação, assuntos constitucionais e audição dos editos dos altos funcionários.

Outro modo de se praticar a democracia deliberativa era reunir todos em um único corpo, neste caso, deliberava-se para a escolha dos altos funcionários; votar as leis; assuntos de guerra e paz; prestação de contas da administração das cidades. Nas formas democráticas de governo, uma última forma de deliberar era a tomada de decisão sobre todas as matérias, em conselhos, limitando-se os funcionários do governo à preparação dos assuntos.

Para Cohen (1989), a noção de democracia deliberativa é um ideal intuitivo de associação democrática em que termos e condições de associação se dão por meio de argumentos públicos, arrazoados entre cidadãos iguais. A democracia deliberativa é uma associação pluralística, seus membros têm preferências, convicções e ideais concernentes com a condução de suas próprias vidas, enquanto disponibilizam consentimento para deliberar resoluções de escolhas coletivas.

A deliberação ideal, segundo Cohen, é livre, no momento em que duas condições são satisfeitas. Primeiro, os participantes se consideram vinculados apenas pelos resultados de sua deliberação e as condições prévias para que haja deliberação. Segundo, os participantes admitem como provável ou possível que eles podem agir, 
a partir dos resultados, ao ter como fato que uma determinada decisão é obtida através da sua deliberação, como uma razão suficiente para cumpri-la. Nas deliberações políticas todas as matérias passíveis de regulação são abrangidas, tendo em vista o interesse de todos.

A idealização de democracia deliberativa como exposta por Joshua Cohen, pressupõe que decisões numa comunidade política são tomadas de forma coletiva, em que atores têm objetivo e um bem em comum, que o resultado alcançado por meio da deliberação atende em geral às necessidades, interesses e preferência de uma dada sociedade. Neste ponto, pode-se fazer uma aproximação entre o pensamento moderno de democracia deliberativa e a deliberação das constituições democráticas da Politeia. Em Política, a deliberação era, em alguns casos, princípios próprios da Constituição e condição mesmo da convivência social e política.

Habermas (1997), não obstante, chama atenção para a falta de enunciados sobre a relação existente entre as deliberações reguladas através do processo democrático e aqueles de formação informal da opinião pública na postulação de Cohen. Esses mesmos processos, na visão de Habermas, organizados neste tipo de espaço, estruturam procedimentos de formação da opinião e da vontade para solução de questões práticas. De outro lado, a esfera pública parlamentar necessita do contexto de descoberta não regulada, através de processos em que reside em geral o cidadão.

Neste sentido, a democracia deliberativa de Habermas se distancia de forma procedimental daquela descrita por Aristóteles. Aqui o resultado da deliberação tem caráter indutivo, em que o resultado da ação comunicativa nas diversas esferas públicas cria ressonância nas instituições que efetivamente têm o poder de deliberar e tomar decisões que irão afetar ou não a comunidade política de forma abrangente. Ou seja, um sistema de democracia representativa. Naquela o sentido da deliberação tem caráter de formação das Leis e afeta diretamente a administração da cidade. Quanto à representação, na democracia, Aristóteles a admite, no entanto a concebe por outras razões:

[...] É vantajoso para o aperfeiçoamento do seu corpo deliberativo que ela se conduza como as oligarquias em relação aos tribunais, [...] e faça o mesmo em relação às assembleias, [...] é igualmente vantajoso para quem delibera ser escolhido pelo voto ou por sorteio por todas as diferentes classes e, se os homens do povo excedem substancialmente a classe política em número, é ainda vantajoso não oferecer remuneração a todos, mas somente a um número equivalente ao dos notáveis, ou então eliminar mediante sorteio os excedentes a este número (1985, p. 1298).

Habermas, ao pensar a representação política, parece estar olhando as questões de escala, ou para a ideia de a impossibilidade do processo deliberativo ser suficiente para gerar governança nas sociedades complexas. A motivação de Aristóteles, nesse assunto, parece estar centrada no jogo do equilíbrio das forças governativas.

Em grande parte, é possível perceber a estrutura do conceito de democracia deliberativa como força capaz de produzir efeitos transformadores na comunidade política, tanto no momento histórico antigo quanto no atual, na concepção de gestão pública pelo modelo de governo democrático 


\section{Participação nas decisões da comunidade política}

Grandes discussões sobre participação da população em política, em sua maioria, giram em torno de quais motivações existentes no sistema político são capazes de fazer o cidadão efetivamente participar. Depois, se a participação popular em grande escala representa ou não algum perigo para a democracia como a existente na atualidade.

Para Giacomo Sani (1998, pp. 888-890) a participação política não deve ficar restrita à designação de uma série de atividades como o ato de votar ou promover manifestações, ou mesmo fazer parte efetivamente, quer seja em atos de militância, ou nas contribuições para com os partidos políticos. Segundo o autor existem pelo menos três formas de atuação política que devem ser consideradas.

Primeiro, a laboração política poderia assim ser considerada apenas com a presença $a^{[4]}$ dos atores sociais em determinadas ocasiões ou circunstâncias, no entanto, nesta forma de participação, a conduta dos atores é pautada por comportamentos excessivamente receptivos, transformando o ato de atuar em uma forma pouco intensa e marginal.

A segunda forma de participação, que Sani denomina ativação, transforma o ator social em um agente de possíveis transformações, momento em que o sujeito desenvolve atividades, ora por iniciativa particular, noutra por delegação de agremiações políticas para participação em movimentos sociais, campanhas eleitorais, nos processos de divulgação das ideologias partidárias e manifestações de protesto.

A participação política, efetiva para o autor, só será considerada quando o indivíduo contribui diretamente para uma decisão política, não obstante considera que, neste caso, a ocorrência de tal participação estaria condicionada a contextos políticos muito restritos. Segundo o autor, "a contribuição é indireta e se expressa na escolha do pessoal dirigente, isto é, do pessoal investido de poder por certo período de tempo para analisar alternativas e tomar decisões que vinculem toda sociedade" (Sani, 1998, p. 889). Não obstante, segundo o autor, para cumprir com o ideal democrático, faz-se necessária a existência de cidadãos atentos, informados e capazes de escolher entre as diversas alternativas apresentadas, e fortemente interessados em todas as formas de participação.

Na contemporaneidade, segundo Carole Pateman (1992), os teóricos da democracia pensam a participação como um mecanismo de proteção. Neste sentido:

A natureza "democrática" do sistema reside em grande parte na forma dos "arranjos institucionais" nacionais, especificamente na composição dos líderes (representantes potenciais) pelos votos, de modo que os teóricos que sustentam tal visão do papel da participação são, antes de mais nada, teóricos do governo representativo (Pateman, 1992, p. 32).

Pateman defende que a democracia participativa revela funções muito mais abrangentes e de ordem fundamental para o estabelecimento e manutenção do Estado democrático.

4. Destacado pelo autor. 
A participação nas Constituições democráticas, em Aristóteles ${ }^{[5]}$, constitui-se na essência mesma da maioria dos sistemas de gestão das cidades, - as pessoas eram inscritas para tomar parte nas decisões das assembleias - neste sentido, a atuação é incentivada por motivações compensatórias pecuniárias para as classes pobres e por isenções de multas por não participação, daquelas consideradas mais abastadas.

O modelo descrito por Aristóteles demonstra, de fato, produzir equilíbrio na condução da atividade governativa da comunidade política, tende a não permitir que determinada classe forme maiorias absolutas. Por conseguinte, produza desigualdade na gestão da coisa pública.

Neste sentido, extrapola ao fato de afetar as atividades da vida cotidiana, pois pode servir de treinamento para "se e quando" o cidadão exercer funções administrativas. A participação, a nível local, na visão de John Stuart Mill (1981), cuida de resolver as objeções quanto à possibilidade real de atuação em sociedades complexas devido a questões de escala. $\mathrm{O}$ autor considera que a localidade é o espaço educativo para o aprendizado no processo de participação política. É por meio da participação a nível local que se aprende os princípios da democracia. Na visão de Mill, será somente ao praticar o governo popular em pequena escala que o povo terá possibilidade de aprender a exercitá-lo em maior escala.

Tocqueville (2005) demonstra como a força da participação popular, que ocorria nas comunas dos Estados Unidos da América, influenciou o processo de construção da democracia. Naquele país, na comuna, lugar em que a ação legislativa e governamental é mais próxima dos governados, não se admitia a representação política. A direção das magistraturas era exercida pelos próprios eleitores e as funções públicas abrangiam grande número, bem divididas entre os comunais. Os poderes administrativos, a seu turno, estavam concentrados nas mãos de poucos atores sociais, eleitos anualmente, os chamados select-man.

Nas Constituições democráticas descritas por Aristóteles ${ }^{[6]}$ o povo é chamado a participar, mesmo que para tal exista a instituição de alguns artifícios como pagamento pecuniário ou aplicação de multa. Resulta disto, a percepção da necessidade de uma vontade geral como uma instituição de soberania popular.

Na visão de Rousseau (2002), a vontade geral é indestrutível:

Enquanto numerosos homens reunidos se consideram como um corpo único, sua vontade também é única e se relaciona com a comum conservação e o bem-estar geral. Todas as molas do Estado são então vigorosas e simples, suas sentenças são claras e luminosas; não há interesses embaraçados, contraditórios; o bem comum mostra-se, por toda parte, com evidência e apenas demanda bom senso para ser percebido (Rousseau, 2002, p. 142).

Concordando com Pateman sobre a inexistência de obrigação imprescindível quanto a uma divisão do conceito moderno e clássico - e antigo, acrescento eu de democracia participativa, tendo em conta ainda o que prescreve Aristóteles, no

5. Idem nota 1 .

6. Idem nota 1. 
sentido que a participação da população em uma comunidade política está intimamente ligada às Constituições democráticas, a democracia é vista desta forma como o resultado mesmo da participação, em todos os tempos.

\section{Democracia e Justiça}

Para Aristóteles ${ }^{[7]}$, na política, o bem é a Justiça traduzida no interesse comum que, em geral, as pessoas consideram como uma espécie de igualdade ${ }^{[8]}$, paridade ao menos para pessoas iguais. No entanto, no pensamento do autor, residem nesta ideia, pelo menos duas questões que devem ser consideradas: Igual em quê? Desigual aonde?

Em Política, Aristóteles entende que todas as Constituições fundamentadas em igualdades e desigualdades generalizadas são desvios da Constituição ideal. Neste sentido, reivindicação de qualquer natureza, seja no sentido do mérito ou superioridade, ou ainda, aquelas por nascimento com pretensões de governo seriam consideradas casos desviantes. A forma correta de reivindicar seria uma que objetivasse a equidade.

[...] E significa correta em relação ao interesse de toda a cidade e ao bem-estar dos cidadãos; cidadão, de um modo geral, é uma pessoa que participa das funções de governo e é governado, embora ele seja diferente, segundo cada forma de governo; em relação à melhor forma, cidadão é uma pessoa dotada de capacidade e vontade de ser governada e governar com vistas a uma vida conforme ao mérito de cada um (1985, p. 1283).

Equidade parece desta forma, nas Constituições democráticas, segundo Aristóteles, uma forma de igualdade que tenha por princípio a observância do bem-estar da comunidade política, que seja destituída de distinções e outros artifícios que possam produzir desigualdades ou igualdades generalizadas.

Não obstante, não parece claro que o autor responda às próprias indagações de forma que não deixe dúvidas, no sentido de definir quais razões tornam os homens iguais ou desiguais, e, até que ponto o fato implica na concepção de abstração o conceito tradicional de Contrato Social.

A questão da Justiça como princípio é enfrentada, na atualidade, por John Rawls (2000). Do mesmo modo que Aristóteles ${ }^{[9]}$, o autor trabalha com a ideia de Justiça equitativa, aqui entendida no sentido que a equidade pode generalizar e elevar a um nível mais alto de equidade.

Em sua construção analítica, John Rawls defende a ideia de dois princípios de Justiça:

Primeiro: cada pessoa deve ter um direito igual ao mais abrangente sistema de liberdades básicas iguais que seja compatível com um sistema semelhante de liberdades para as outras. Segundo: as desigualdades sociais e econômicas

7. Idem nota 1.

8. Aristóteles, a despeito do tema igualdade, defendia em sua época, o instituto da escravidão de humanos.

9. Idem nota 1 . 
devem ser de tal modo que sejam ao mesmo tempo (a) consideradas como vantajosas para todas dentro do limite do razoável, e (b) vinculadas a posições e cargos acessíveis a todos (Rawls, 2000, p. 64).

Em tese, a concepção geral de Justiça, de Rawls não torna necessária a existência de restrições quanto ao tipo de desigualdades permissíveis; apenas exige que a posição de todos seja melhorada.

Como explicitado na citação acima, os princípios são da ordem dos direitos e liberdades fundamentais do cidadão, por um lado, e dos benefícios sociais e econômicos, do outro. Para cumprir as exigências do primeiro caso, necessário faz-se que certos tipos de regras se apliquem igualmente a todos e permitam a mais abrangente liberdade compatível com uma liberdade igual para todos.

Para interpretar o segundo princípio, Rawls institui uma explicação esquemática. Tal procedimento faz sentido, haja vista, as frases "vantajosas para todos" e "igualmente abertas a todos" serem, segundo o autor, ambíguas e terem sentidos concorrentes, derivando em quatro interpretações dos dois princípios.

A primeira expressão, traduzida como liberdade igual, dentro do esquema proposto pelo autor tem sempre o mesmo sentido: igualdade como carreiras abertas a talentos e igualdade de oportunidades equitativas. Para a expressão seguinte, o autor trabalha com três interpretações representadas pelo sistema de liberdade natural, igualdade liberal e igualdade democrática. Atendendo aos objetivos deste artigo, nossa análise ficará restrita à igualdade democrática.

Nas democracias, "a ordem social não deve estabelecer e assegurar as perspectivas mais atraentes dos que estão em melhores condições a não ser que, fazendo isso, traga também vantagem para os menos afortunados.” (Rawls, 2000, p. 80)

Dentro da perspectiva da Justiça na ordem democrática, e, tomando como ponto de análise o indivíduo, parece ser possível encontrar equidade dentro da proposição teórica de Rawls, principalmente no sentido em que a liberdade é tratada como uma constante disponível para todos. No entanto, parece difícil conciliar ganhos efetivos para pessoas que se encontram em condições sociais privilegiadas, ao passo que outras nem tanto, mesmo reconhecendo que este posicionamento vá de encontro aos argumentos bastante convincentes da exposição do autor.

Os argumentos de Aristóteles ${ }^{[10]}$ sobre Justiça equitativa são no sentido de equilibrar igualdade e desigualdade, tanto na percepção de possíveis ganhos obtidos pela condição de se viver em sociedade, quanto nas situações de disputas para exercer função de governo. Equidade para Rawls é no sentido de, admitindo-se a impossibilidade do equilíbrio entre igualdade e desigualdade, que esta seja diminuída por possíveis ganhos dos menos afortunados em cada situação de vantagem dos que estiverem em melhores condições.

A construção de uma teoria da Justiça para o modelo de governo democrático parece enfrentar dificuldades de concepção teórica em qualquer momento histórico. Não obstante, ao enfrentar o assunto, tanto Aristóteles quanto John Rawls parecem 
tomar a mesma direção no sentido de buscar, na equidade, uma possível solução para o desequilíbrio entre igualdade e desigualdade.

De forma complementar, contrapondo aos pensamentos citados, Amartya Sen (2010), expõe uma visão de Justiça que obriga sua realização em ao menos três quesitos: (1) forma de promoção da Justiça; (2) capacidade de decisão; (3) reconhecimento da negação da Justiça.

Em primeiro lugar, para se analisar a teoria de Justiça, a partir da visão racional prática, será necessário incluir na análise meios para formação de juízos no sentido de promovê-la, ao mesmo tempo em que se procuram formas de reduzir a injustiça. Segundo Sen, não faz sentido apenas construir tipos ideais de sociedades perfeitamente justas, como é a prática atual de muitas teorias da Filosofia Política.

Em segundo lugar, faz-se necessário admitir a existência de diferentes razões de Justiça, com cada uma delas conseguindo avançar, mesmo sob o crivo de avaliações críticas e conclusões divergentes.

Por último, o autor entende que a presença de injustiças, que podem ser reparadas, pode estar relacionada não com deficiências institucionais, mas enquanto transgressões do comportamento. Para o autor, a Justiça está ligada na forma como a vida vai transcorrendo, não somente dentro da rigidez das instituições.

Ao desenvolver sua argumentação a respeito dos conceitos de Justiça e Democracia, Amartya Sen preocupa-se mais com a perspectiva de vida e as liberdades das pessoas envolvidas, e, com menor preocupação, no sentido de definir os princípios do direito em termos de instituições. Não obstante, como reforça o próprio autor, as instituições enquanto determinantes da formação do comportamento do indivíduo e da sociedade desempenham papel instrumental de significativa relevância na busca da razão. Neste sentido, uma escolha adequada das instituições implica no sucesso da ampliação e do reforço da ideia de lei.

Para a explanação de Sen, a democracia é vista, em termos de argumentação pública, traduzida pela compreensão dessa forma de gestão como um regime de "governo pela discussão" [11]. Sem prejuízo de enxergar a democracia como um instrumento utilizado para reforçar a participação ou alguma forma de comprometimento discursivo, em que a interação entre os atores sociais é sustentada por meio da expansão das possibilidades da troca de informações. Outro ponto importante é a necessidade de se formar juízo acerca da democracia a partir de diferentes vozes emanadas do seio popular, não somente, tendo em vista os ruídos provocados pelas instituições existentes.

Sen busca contrapor algumas das teorias da Justiça que concentram seus esforços argumentativos em formas de se fundar instituições justas, deixando os aspectos comportamentais dos atores sociais para um papel derivado das instituições e subsidiário - "como a perspectiva, de John Rawls que via a "justiça como fairness" ou equidade, e que é merecidamente aclamada, fornecendo um conjunto único de "princípios de justiça” preocupados exclusivamente com a edificação de "instituições justas" (Sen, 2009, p.14) — na construção do tecido social, lugar em que está inserido

11. Destacado pelo autor. 
o pensamento de Justiça e Democracia. Neste sentido, Amartya Sen propõe a existência de inadequações que parecem cruciais em uma perspectiva de teoria de Justiça que opte por dedicar, de forma dominante, seu foco nas instituições, em detrimento de concentrar o foco das atenções analíticas na forma de vida que as pessoas vão construindo.

\section{Conclusão}

Desde Aristóteles busca-se construir um conceito sobre a forma democrática de governar, a respeito de como pode sofrer variação, saindo de formas completamente fechadas para aquelas onde a participação e a contestação pública são o ponto máximo de um modelo ideal. Mais que isso, busca-se compreender como o processo de deliberação contribui para a formação das sociedades políticas, e, se é possível um princípio de Justiça equitativa na forma democrática de governo. Naquele momento como nesse, a comunidade humana, política, tenta encontrar formas de governo que possibilitem reduzir pelas Constituições políticas, as diferenças produzidas pela opção da convivência coletiva. Posto que, somos atraídos pela manutenção de privilégios adquiridos ou conquistados, trabalhamos para que os códigos de nossas constituições políticas que tratam das relações de poder, ao longo do tempo, sejam reproduzidos com pouca ou nenhuma alteração. Neste sentido parece evidente que, desconsiderando as questões de gradação ou escala, os problemas da sociedade humana permanecem inalterados e por isso conexos e atemporal.

\section{Referências}

Aristóteles. (1985). A Política (M. Kury, Trans.). Brasília, Brasil: UnB.

Cohen, J. (1989). Deliberation and democratic legitimacy. In Harmlin A. \& Petit P. (Eds.), The good polity. Oxford, United Kingdom: Blackwell.

Dahl, R. (2012). Poliarquia: participação e oposição (1 ${ }^{\text {st }}$ ed.) (C. Paciornik, Trans.). São Paulo, Brasil: EDUSP.

Gutmann, A. (1995). A desarmonia da Democracia. Lua Nova, 36, 5-37.

Habermas, J. (1997). Direito e democracia: entre facticidade e validade (F. Siebeneichler, Trans.). Rio de Janeiro, Brasil: Tempo Brasileiro.

Mill, J. S. (1981). Considerações sobre o governo representativo (M. Santos Jr., Trans.). Brasília, Brasil: UnB.

Pateman, C. (1992). Participação e teoria democrática (L. Rouanet, Trans.). São Paulo, Brasil: Paz e Terra.

Rawls, J. (2000). Uma teoria da justiça (1st ed.) (A. Pisetta \& L. Esteves, Trans.). São Paulo, Brasil: Martins Fontes.

Rousseau, J. J. (2002). Do contrato social (R. Roque da Silva, Trans.). Brasil: Ridendo Castigat Mores. Disponível em <http://www.ebooksbrasil.org/eLibris/contratosocial.html>.

Sani, G. (1998). Participação política. In Bobbio, N., Matteucci, N. \& Pasquino, G. (Eds.), Dicionário de política (1 ${ }^{\text {st }}$ ed.) (pp. 888-890). Brasília, Brasil: UnB. 
Sartori, G. (1994). A teoria da democracia revisitada (1 ${ }^{\text {st }}$ ed.) (A. Candido, Trans.). São Paulo, Brasil: Editora Ática.

Sen, A. (2009). A ideia de justiça. (N. Bastos, Trans.). Coimbra, Portugal: Almedina S.A.

Tocqueville, A. (2005). A democracia na América (2 ${ }^{\text {nd }}$ ed.). São Paulo, Brasil: Martins Fontes.

\section{Sobre o autor}

IVANILDO BEZERRA DE MEDEIRos é Bacharel Ciências Sociais com habilitação em políticas públicas (2012) e Mestre em Ciência Política pela Universidade Federal de Goiás. Os seus trabalhos publicados incluem Desenvolvimento regional no federalismo brasileiro: a desigualdade provocada (Dissertação de Mestrado, 2015) e "Desenvolvimento regional no federalismo brasileiro: Políticas para Educação", na Revista Brasileira de Gestão e Desenvolvimento Regional, v. 13, n. 3 (2017). Participou também na terceira edição do congresso internacional AMECIP em Toluca, México.

\section{About the author}

IVANILDO BEZERRA DE MEDEIROs holds a bachelor's degree in Social Sciences with qualification in public policies (2012) and a master's in Political Science from the Federal University of Goiás. His works include Regional Development on Brazilian Federalism: A Provoked Inequality (Master's Dissertation, 2015) and "Regional Development in Brazilian federalism: Policies for Education" in the Brazilian Journal of Regional Management and Development, vol. 13, no. 3 (2017). He has also participated in the third edition of the international congress AMECIP in Toluca, Mexico. 